Arq. Bras. Med. Vet. Zootec., v.68, n.2, p.299-306, 2016

\title{
Description of Methicillin-resistant Staphylococcus pseudintermedius from canine pyoderma in Minas Gerais state, Brazil
}

[Descrição de Staphylococcus pseudintermedius meticilina-resistentes de piodermite canina no estado de Minas Gerais, Brasil]

E. Bourguignon, G.N. Viçosa, C.M.M. Corsini, M.A.S. Moreira, L.A. Nero, L.G. Conceição

Universidade Federal de Viçosa - Viçosa, MG

\begin{abstract}
Methicillin-resistant Staphylococcus pseudintermedius (MRSP) is of worldwide concern in veterinary medicine. The identification of resistant strains is necessary for proper treatment and the prevention of its propagation among animals. This study aimed to identify S. pseudintermedius isolated from canine pyoderma and evaluate their resistance profiles. Lesions from 25 dogs with pyoderma were sampled. Bacterial isolates were subjected to phenotypic and genotypic analysis for identification of the causative agent. $S$. pseudintermedius isolates were subjected to SmaI macrorestriction analysis and PFGE for genetic grouping, and PCR to identify the presence of the mecA gene. Their resistance profiles against 12 antimicrobials were also assessed. According to the microbiological analysis, 70 of the 75 isolates obtained were $S$. pseudintermedius. The isolates presented PFGE patterns, with similarity varying between 84.6 and $100 \%$, and were grouped into 19 clusters. Despite a high frequency of mecA-positive isolates (66 out 70), only 12 presented resistances to oxacillin. Multi-resistance was identified in 29 isolates. The high frequency of MRSP isolated in this study highlights the relevance of identifying resistant strains to lead proper clinical treatment.
\end{abstract}

Keywords: Staphylococcus pseudintermedius, canine pyoderma, mecA, PFGE, antimicrobial resistance

\section{RESUMO}

Staphylococcus pseudintermedius meticilina-resistente (MRSP) é de preocupação mundial na medicina veterinária. A identificação de cepas resistentes é necessária a um tratamento adequado e à prevenção da sua propagação entre os animais. O objetivo do estudo foi identificar S. pseudintermedius isolados de piodermite canina e avaliar o perfil de resistência. Foram coletadas amostras de lesões de 25 cães com piodermite. Os isolados bacterianos foram submetidos a análises fenotípicas e genotípicas para identificação do agente causador. Isolados de S. pseudintermedius foram submetidos à análise de macrorrestrição por SmaI e PFGE para agrupamento genético e à PCR para identificar a presença do gene mecA. Seu perfil de resistência contra 12 antimicrobianos também foi avaliado. De acordo com a análise microbiológica, 70 dos 75 isolados obtidos foram identificados como S. pseudintermedius. Os isolados apresentaram padrões de PFGE com similaridade variando entre 84.6 e 100\% e foram agrupados em 19 grupos genéticos. Apesar da frequência alta de isolados mecA positivos (66 em 70), apenas 12 apresentaram resistência à oxacilina. Multirresistência foi identificada em 29 isolados. A alta frequência de MRSP isolados neste estudo destaca a relevância de se identificarem cepas resistentes para se conduzir um tratamento clínico adequado.

Palavras-chave: Staphylococcus pseudintermedius, piodermite canina, mecA, PFGE, resistência antimicrobiana

\section{INTRODUCTION}

Staphylococcus pseudintermedius is considered the most frequently isolated agent from canine pyoderma (Devriese et al., 2009), being the most common reason for antimicrobial use in dogs. The Staphylococcus genus is characterized by its easy development of antimicrobial

Recebido em 7 de fevereiro de 2015

Aceito em 15 de novembro de 2015

E-mail: elisa.dermatovet@gmail.com resistance (Guardabassi et al., 2004; Weese and van Duijkeren, 2010). Methicillin-resistant staphylococci (MRS) are resistant to cephalosporins, amoxicillin/clavulanic acid, imipenem, ampicillin/sulbactam and other $\beta$-lactam antimicrobials. For proper characterization, the acronym MRS is commonly used, although oxacillin is currently the agent of choice for resistance testing (CLSI, 2008). 
Methicillin-resistant S. aureus (MRSA) and methicillin-resistant $S$. pseudintermedius (MRSP) are of great concern in veterinary medicine and public health (Weese and van Duijkeren, 2010). In dogs with pyoderma, the occurrence of MRSP may vary between 0 and 66\% (Medleau et al., 1986; Kania et al., 2004; Sasaki et al., 2007; Griffeth et al., 2008; Kawakami et al., 2010).

The most reliable test to identify MRS is a PCR protocol targeting the mecA gene, which encodes the supplemental penicillin-binding protein, PBP2a (Schissler et al., 2009). This protein is expressed either homogeneously, which is easily detected with standard testing methods, or heterogeneously, which is more difficult to detect with those methods, since only a fraction of the population expresses the resistance phenotype (Bemis et al., 2006). This study aimed to characterize $S$. pseudintermedius isolates from canine pyoderma by phenotypic and genotypic methods, and evaluate their resistance profiles to antimicrobials and the presence of the mecA gene.

\section{MATERIAL AND METHODS}

Twenty-five dogs from different households attended at the dermatology sector of a Veterinary Hospital located in Minas Gerais State, Brazil, were selected for this study. The inclusion criteria were clinical signs of either superficial or deep pyoderma, associated with positive skin cytology for bacterial organisms. None of the animals had received topical or systemic antimicrobial treatment for at least three weeks prior to sampling. Owner consent was obtained before animal inclusion in the study. This work was approved by the Bioethics Committee and/or Biosecurity, protocol number 11/2011. Clinical samples were collected from typical lesions, such as pustules, epidermal colarettes, draining tracts or under crusts, using a sterile swab. The sampling was performed carefully to avoid contamination with nonpathogenic microorganisms, as previously described by Ihrke (1987) and White, et al. (2005). Information about previous antimicrobial use was obtained from dermatologic medical records.

The swabs obtained were immersed in $1 \mathrm{~mL}$ of $0.85 \% \mathrm{NaCl}(\mathrm{w} / \mathrm{v})$ and stirred vigorously. Then, $200 \mu \mathrm{L}$ aliquots were streaked with a sterile swab on sheep blood agar (5\% v/v) and MacConkey Agar (Oxoid Ltd., England) simultaneously and incubated at $37^{\circ} \mathrm{C}$ for $24 \mathrm{~h}$. Three isolated colonies of the samples obtained from each animal were transferred to brain heart infusion (BHI, Oxoid, England) broth, incubated at $37^{\circ} \mathrm{C}$ for $24 \mathrm{~h}$, and then aliquoted before being stored in $20 \%$ glycerol $(\mathrm{v} / \mathrm{v})$ at $-80^{\circ} \mathrm{C}$. As guidance, the dogs were identified with numbers 01 to 25 , and their respective isolates using the animal number followed by 1,2 and 3 .

After sample collection all isolates were subjected to phenotypic and biochemical tests (Gram staining, catalase, oxidase and coagulase production, haemolysis, maltose and mannitol fermentation and Baird-Parker agar growth) for a preliminary identification. The isolates were also subjected to phenotypic identification using API Staph and the Apiweb V4.1 database (BioMérieux SA, France).

DNA was extracted from the isolates using the Wizard Genomic DNA Purification Kit (Promega Corp., USA). The obtained DNA was subjected to PCR-RFLP for SIG identification, using the Bannoehr et al. (2009) method. PCR reactions targeting the pta gene were prepared at a final volume of $50 \mu \mathrm{L}$, composed of $2 \mu \mathrm{L}$ of DNA, $25 \mu \mathrm{L}$ of the GoTaq Green Master Mix (Promega Corp., USA), $1 \mu \mathrm{L}$ of each primer (F1: AAAGACAAACTTTCAGGTAA and R1:GCATAAACAAGCATTGTACCG, both at $10 \mathrm{pmol} / \mu \mathrm{L})$, and $21 \mu \mathrm{L}$ of PCR ultra-pure water (Promega Corp., USA). The PCR conditions were $95{ }^{\circ} \mathrm{C}$ for $2 \mathrm{~min}, 30$ cycles of $95^{\circ} \mathrm{C}$ for $1 \mathrm{~min}, 53^{\circ} \mathrm{C}$ for $1 \mathrm{~min}, 72^{\circ} \mathrm{C}$ for $1 \mathrm{~min}$, and $72^{\circ} \mathrm{C}$ for $7 \mathrm{~min}$. Twenty-five-microliter aliquots of amplification products were added to $5 \mathrm{U}$ of the MboI macrorestriction enzyme (New England Biolabs Inc., USA) and $5 \mu \mathrm{L}$ of its digestion buffer, before being incubated at $37^{\circ} \mathrm{C}$ for $2 \mathrm{~h}$. Digested PCR products were subjected to electrophoresis on $2.0 \%(\mathrm{w} / \mathrm{v})$ agarose gels in $0.5 \times$ Tris/Borate/EDTA (TBE) buffer, stained with GelRed (Biotium Inc., USA), and visualized in a transilluminator. S. pseudintermedius MRSP 3279 and S. aureus USA 100 were used as positive and negative controls, respectively.

Isolates that presented typical phenotypic characteristics and PCR-RFLP products with 213 and $107 \mathrm{bp}$ were identified as $S$. pseudintermedius. 
Isolates identified as $S$. pseudintermedius were subjected to macrorestriction by SmaI (Promega Corp., USA) and PFGE to determine their genetic relationships (Hauschild and Wójcik, 2007; Fazakerley et al., 2010). Agarose plugs were prepared as described by Mulvey, et al. (2001) and the electrophoresis conditions were 1$10 \mathrm{~s}$ pulse time, $6 \mathrm{~V} / \mathrm{cm}, 120^{\circ}$ angle, $14^{\circ} \mathrm{C}$ for $22 \mathrm{~h}$, using the Pulse Marker ${ }^{\mathrm{TM}} 50-1,000 \mathrm{~kb}$ as the molecular weight marker (Sigma-Aldrich, USA). Gels were stained with GelRed ${ }^{\mathrm{TM}}$ (Biotium Inc., USA) and visualized in a transilluminator under UV light. The obtained bands were analyzed using BioNumerics software v. 6.6.4 (Applied Maths, Belgium). A dendrogram was obtained with the average linkage method (UGPMA), using the Dice coefficient with 5\% tolerance. Clusters were defined considering 95\% of similarity.

The antimicrobial resistance assay was performed according to the CLSI (2008) method. Isolates identified as $S$. pseudintermedius were streaked on BHI agar (Oxoid Ltd., England) plates and incubated at $37^{\circ} \mathrm{C}$ for $24 \mathrm{~h}$. Isolated colonies were transferred to BHI broth (Oxoid Ltd., England) and incubated at $37^{\circ} \mathrm{C}$. The turbidity of active growing broth cultures was adjusted to the MacFarland turbity standard of 0.5 . The obtained cultures were streaked on Mueller-Hinton (Oxoid Ltd., England) plates, and the disks containing antimicrobials were placed on each plate at equivalent distances (maximum five per plate). Each assay was performed in duplicate, and then incubated at $37^{\circ} \mathrm{C}$ for $24 \mathrm{~h}$. Plates containing oxacillin were incubated at $35^{\circ} \mathrm{C}$ for $24 \mathrm{~h}$. After incubation, inhibition zones were recorded using a caliper graph (CLSI, 2008). The following antimicrobials were tested: amoxicillin $(10 \mu \mathrm{g})$, amoxicillin + clavulanic acid $(30 \mu \mathrm{g})$, azithromycin $(15 \mu \mathrm{g})$, cefaclor $(30 \mu \mathrm{g})$, cephalexin $(30 \mu \mathrm{g})$, ciprofloxacin $(5 \mu \mathrm{g})$, clindamycin $(2 \mu \mathrm{g})$, doxycycline $(30 \mu \mathrm{g})$, enrofloxacin $(30 \mu \mathrm{g})$, imipenem $(10 \mu \mathrm{g})$, oxacillin $(1 \mu \mathrm{g})$, and sulfadiazine + trimethoprim $(25 \mu \mathrm{g})$ (Cefar Diagnostics Ltda, Brazil). The inhibition zone diameters were evaluated using the CLSI method (CLSI, 2008) and the manufacturer's recommendations (Cefar Diagnostics Ltda, Brazil). Bacterial inhibition zones were measured using the interpretive criterion of $\leq 17 \mathrm{~mm}$ for oxacillin resistance, as proposed by Schissler, et al. (2009). S. aureus ATCC 29213 was used as a control for antimicrobial susceptibility as recommended by Olsson-Liljequist, et al. (2002).

DNA from all S. pseudintermedius isolates was subjected to PCR to identify the presence of the mecA gene, according to Bannoehr, et al. (2007). $\mathrm{PCR}$ reactions were performed in a final volume of $25 \mu \mathrm{l}$ containing $2 \mu \mathrm{l}$ of DNA, $12.5 \mu \mathrm{l}$ of the GoTaq green Master Mix (Promega Corp., USA), $8.5 \mu 1$ of nuclease-free water, and $1 \mu \mathrm{l}$ of each primer (F1: GTAGAAATGACTGAACGTCCGATAA and R1: CCAATTCCACATTGTTTCGGTCTAA, both at $10 \mathrm{pmol} / \mu \mathrm{L})$. PCR conditions consisted of an initial denaturation for $5 \mathrm{~min}$ at $95^{\circ} \mathrm{C}$, followed by 30 cycles of denaturation for $45 \mathrm{~s}$ at $95^{\circ} \mathrm{C}$, annealing for $45 \mathrm{~s}$ at $52^{\circ} \mathrm{C}$, extension for $1 \mathrm{~min}$ at $72^{\circ} \mathrm{C}$ and a final extension for $5 \mathrm{~min}$ at $72^{\circ} \mathrm{C}$. Five-microliter aliquots of amplification products were electrophoresed on $2.0 \%(\mathrm{w} / \mathrm{v})$ agarose gels in $0.5 \times$ TBE buffer, stained with GelRed (Biotium Inc., USA), and visualized in a transilluminator. S. pseudintermedius MRSP 3279 and $S$. aureus USA 100 were used as positive and negative controls, respectively. Isolates that presented a PCR product with 310 bp were classified as positive for mecA.

\section{RESULTS}

According to the medical records of the dogs that were included in the study, nine individuals had previous antimicrobial use and cephalexin was the most commonly used (seven dogs). The previous antimicrobial use of the other 16 animals was not determined.

Considering the microbiological analysis, 70 of the 75 isolates obtained from 25 animals were identified as $S$. pseudintermedius and the other five isolates were classified as Staphylococcus sp. (isolates number 3.1, 6.1, 6.2, 6.3 and 16.2). These five isolates were not included in the present study.

A total of 67 isolates presented SmaI macrorestriction patterns (except isolates 7.2, 7.3 and 11.2), with similarity among them varying between 84.6 and $100 \%$ (Figure 1). The isolates were clustered in two major groups, one composed by 12 isolates (sharing similarity indexes between 85.6 to $100 \%$ ) and the other by 55 isolates (similarity indexes between 86.4 and $100 \%$ ). In addition, the isolates were grouped considering a similarity index of $85 \%$, resulting in a total of 19 clusters (Figure 1). 


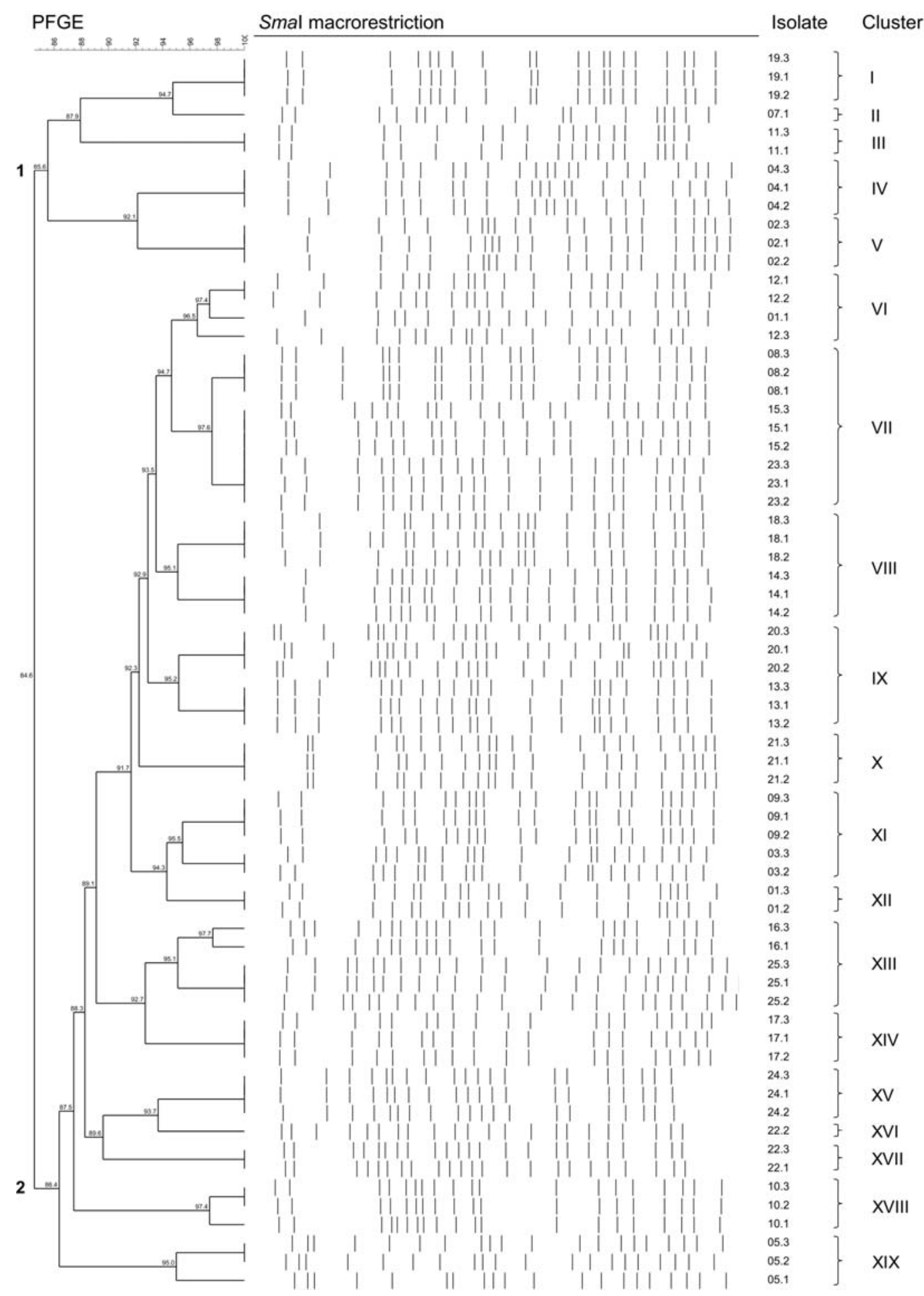

Figure 1. Schematic representation of the obtained PFGE profiles after DNA macrorestriction (SmaI) of Staphylococcus pseudintermedius isolates obtained from canine pyoderma. Similarities between the identified PFGE profiles were estimated using the Dice coefficient (5\% tolerance); 2 major groups (1 and 2) were established, and 19 clusters (I to XIX) were defined considering 95\% similarity. 
Based on PCR analysis for mecA, 66 out of 70 presented positive results; only isolates 08.1, 08.2, and 23.3 from cluster VII and isolate 13.2 from cluster IX were negative (Figure 1). In addition, all animals included in this study showed at least one MRSP strain.

Results for antimicrobial susceptibility and resistance patterns of the isolates within the two major groups obtained by PFGE are presented in Table 1 and 2, respectively. None of the tested isolates displayed resistance to imipenem and 12 presented resistance to oxacillin. Amoxicillin was the antimicrobial with the highest number of resistant isolates (47/67) (Table 1). Three isolates from PFGE group 1 combined with 8 isolates from PFGE group 2 showed multi-resistance to at least 8 out of 12 antimicrobials tested; thus, 29 out of 67 isolates $(43.3 \%)$ were identified as multi-resistant (Table 2).

Table 1. Individual susceptibility to antimicrobials by Staphylococcus pseudintermedius isolates obtained from canine pyoderma, grouped in two groups with $85 \%$ similarity by SmaI macrorestriction profiles (Figure 1)

\begin{tabular}{|c|c|c|c|c|c|c|}
\hline \multirow[t]{2}{*}{ Antimicrobial } & \multicolumn{3}{|c|}{$\begin{array}{l}\text { Group } 1 \\
(\mathrm{n}=12 \text { isolates })\end{array}$} & \multicolumn{3}{|c|}{$\begin{array}{l}\text { Group } 2 \\
(\mathrm{n}=55 \text { isolates })\end{array}$} \\
\hline & $\mathrm{R}$ & I & $\mathrm{S}$ & $\mathrm{R}$ & I & $\mathrm{S}$ \\
\hline Oxacillin & 3 & 0 & 9 & 8 & 0 & 47 \\
\hline Amoxicillin & 4 & 0 & 8 & 43 & 0 & 12 \\
\hline Amoxicillin and Clavulanic acid & 2 & 0 & 10 & 6 & 0 & 49 \\
\hline Clindamycin & 3 & 1 & 8 & 16 & 0 & 39 \\
\hline Azithromycin & 4 & 0 & 8 & 16 & 0 & 39 \\
\hline Sulfadiazine and trimethoprim & 4 & 0 & 8 & 24 & 0 & 31 \\
\hline Cephalexin & 3 & 0 & 9 & 4 & 0 & 51 \\
\hline Enrofloxacin & 3 & 1 & 8 & 13 & 0 & 42 \\
\hline Imipenem & 0 & 0 & 12 & 0 & 0 & 55 \\
\hline Doxycycline & 0 & 0 & 12 & 11 & 8 & 36 \\
\hline Cefaclor & 3 & 0 & 9 & 6 & 1 & 48 \\
\hline Ciprofloxacin & 3 & 0 & 9 & 13 & 0 & 42 \\
\hline
\end{tabular}

R: resistant, I: intermediary, S: sensitive. * Isolates that did not present SmaI digestion pattern, one strain presented simultaneous resistance to Oxacillin, Amoxicillin, Amoxicillin and Clavulanic acid.

Table 2. Multiple resistance patterns related to distinct combinations of antimicrobials of Staphylococcus pseudintermedius isolates obtained from canine pyoderma, according to PGFE SmaI macrorestriction profiles (85\% similarity, Figure 1$)$

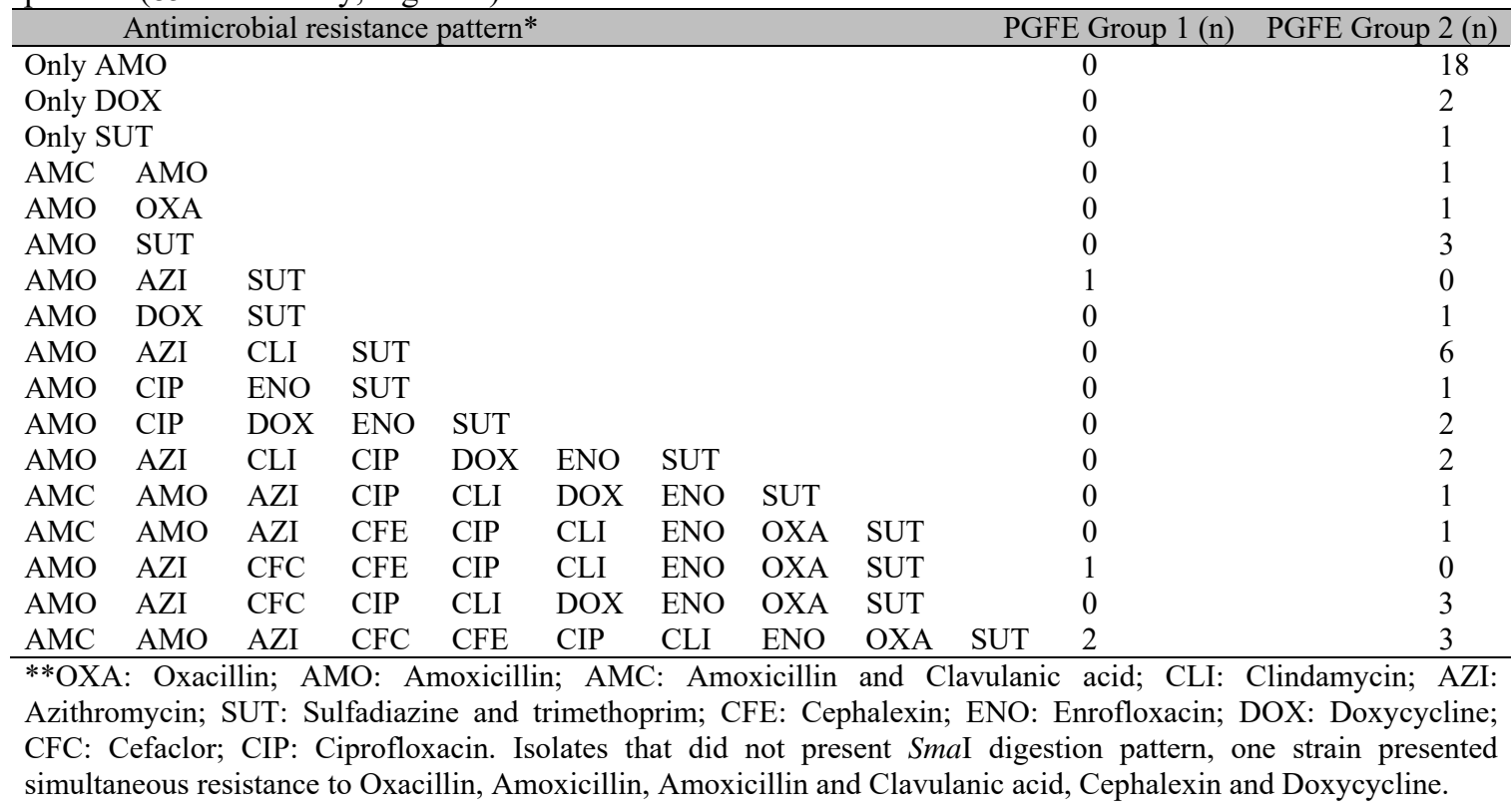




\section{DISCUSSION}

As expected, $93.3 \%(70 / 75)$ of the isolates from 25 dogs with superficial and deep pyoderma were $S$. pseudintermedius, since it is the most common agent isolated from canine pyoderma (Devriese et al., 2009). All three isolates from animal 6 were identified as S. pseudintermedius by phenotypic methods but could not be identified using PCR-RFLP. Two isolates (3.1 and 16.2) were coagulase negative, probably being contaminants in the lesions.

Considering SmaI macrorestriction and PFGE (Fig. 1), most of the isolates from the same animal presented a DNA digestion pattern with $100 \%$ similarity, with some exceptions: isolate 12.3 presented $96.5 \%$ similarity with 12.1 and 12.2 , and isolate 01.1 presented $91.7 \%$ similarity with 01.2 and 01.3. Another study that evaluated isolates from lesions of atopic dermatitis in dogs also found that isolates from the same animal were often related or even identical based on PFGE (Fazakerley et al., 2010). Two different animals (15 and 23) shared the same strain (100\% similarity), even though they came from different households with no apparent contact between them.

The antimicrobials used in this study were selected because of their wide use in small animal medicine, with the exception of imipenem, which, despite being an injectable $\beta$ lactam with little use in veterinary medicine, was selected due to its high antibacterial activity (Rees, 1999). In this study, all isolates were susceptible to imipenem, even those resistant to oxacillin, confirming its antimicrobial activity (Tab. 1). Ruscher, et al. (2009) obtained similar sensitivity results, demonstrating the effectiveness of imipenem over $S$. pseudintermedius. The high prevalence of acquired resistance has limited the role of nonpotentiated amoxicillin in small animal medicine (Ihrke, 1987). Amoxicillin presented the highest resistance index among the isolates of this study (Tab. 1), indicating that this antimicrobial should be avoided when treating $S$. pseudintermedius infections. Cephalexin is considered the first choice in the treatment of pyoderma because it is safe and effective (Toma et al., 2008). This antimicrobial was used in seven out of nine animals that had been previously treated with antimicrobials. Nevertheless, it exhibited the second lowest resistance index in this study (11.4\%, Tab. 1). Only one animal previously treated with cephalexin showed resistant isolates to this antimicrobial drug.

In a previous study, Loeffler, et al. (2007) presented 12 multi-resistant isolates of $S$. pseudintermedius obtained from skin and ear infections with six different resistance profiles, which were resistant to at least 10 of the antimicrobials tested. In the present study, 50 isolates were shown to be resistant to at least one antimicrobial, 15 of these were resistant to five or more antimicrobials (Table 2). Although only $4(33.3 \%)$ isolates belonging to PFGE group 1 showed resistance to the antimicrobials tested, 3 of these isolates were resistant to 9 or more antimicrobials (Table 2). Considering PFGE group 2, 20 out of 55 isolates $(83.7 \%)$ were resistant to more than 3 antimicrobials, and 8 of them were resistant against nine or more antimicrobials (Table 2). Resistant isolates presented highly diverse resistance profiles, which may restrict the range of antimicrobial agents to be used in the treatment of S. pseudintermedius infections. Resistance to oxacillin has been described to be frequently associated with resistance to other groups of antibiotics such as macrolides, lincosamides, aminoglycosides, fluoroquinolones, and sulphonamides (Bond and Loeffler, 2012), and in the present study this association was observed (Table 2).

Even when using a more rigorous interpretation criteria for the resistance to oxacillin $(\leq 17 \mathrm{~mm}$ inhibition zone) (Schissler et al., 2009), the obtained results demonstrated a large difference between the disk diffusion test $(17.1 \%)$ and the detection of the mecA gene (94.3\%). The discrepancy between the presence of mecA and the absence of corresponding oxacillin resistance has been previously noted in other studies (Bemis et al., 2006; Schissler et al., 2009; Feng et al., 2012). The presence of mecA positive $S$. pseudintermedius and $S$. aureus isolates that were susceptible to oxacillin was previously described (Forbes et al., 2008; Feng et al., 2012). Our findings suggest that the MRSP isolates in the present study are probably not expressing the resistance gene in vitro and studies that monitor the antimicrobial treatment of the animals with these strains would be necessary to elucidate the behavior of the bacteria in vivo. 
Isolates that presented identical SmaI macrorestriction profiles $(100 \%$ similarity $)$ tended to display the same antimicrobial resistance profile and presence of mecA. Only the isolates $08.1,08.2,23.3$ and 14.2 were mecA negative when other isolates that shared identical SmaI macrorestriction profiles were mecA positive. These results indicate that resistance patterns may be independent of genotypic clustering, as previously described by Hartmann, et al. (2005).

The frequency of MRSP detected in the present study $(94.3 \%)$ was much higher than those observed in similar studies (Medleau et al., 1986; Kania et al., 2004; Sasaki et al., 2007; Griffeth et al., 2008; Kawakami et al., 2010), which leads to an important concern in Veterinary Medicine in Brazil. Kawakami, et al. (2010) also found a high percentage of MRSP isolates (66.5\%) derived from dogs with pyoderma through the investigation of the mecA gene. Other studies evaluated isolates from healthy skin revealing smaller percentages (Hartmann et al., 2005; Fazakerley et al., 2010; Onuma et al., 2012), which may explain the differences in our results that evaluated isolates from clinical lesions (Table 1).

Further studies are necessary to monitor the outcome of antimicrobial therapy over a prolonged time to evaluate recurrences of canine pyoderma and to compare in vitro antimicrobial susceptibility with in vivo results. The results of this study indicate the importance of conducting a culture and sensitivity test to determine the best treatment and prevent the emergence of multiresistant strains. It also highlights the fact that molecular tools are probably needed for an accurate detection of MRSP.

\section{CONCLUSION}

The present study demonstrates the genetic variability of the $S$. pseudintermedius isolates from canine pyoderma through SmaI macrorestriction and PFGE analysis and the multi-resistance of several isolates to commonly used antimicrobials.

\section{ACKNOWLEDGMENTS}

The authors would like to thank CNPq, CAPES, FAPEMIG and FUNARBE for financial funding and Dr. J.R. Fitzgerald (Roslin Institute and Centre for Infectious Diseases, University of Edinburgh, Edinburgh, UK) for providing the $S$. pseudintermedius MRSP 3279 strain.

\section{REFERENCE}

BANNOEHR, J.; BEN ZAKOUR, N.L.; WALLER, A.S. et al. Population genetic structure of the Staphylococcus intermedius group: Insights into agr diversification and the emergence of methicillinresistant strains. J. Bacteriol., v.189, p.8685-8692, 2007.

BANNOEHR, J.; FRANCO, A.; IURESCIA, M. et al. Molecular diagnostic identification of Staphylococcus pseudintermedius. J. Clin. Microbiol., v.47, p.469471, 2009 .

BEMIS, D.A.; JONES, R.D.; HIATT, L.E. et al. Comparison of tests to detect oxacillin resistance in Staphylococcus intermedius, Staphylococcus schleiferi, and Staphylococcus aureus isolates from canine hosts. J. Clin. Microbiol., v.44, p.3374-3376, 2006.

BOND, R.; LOEFFLER, A. What's happened to Staphylococcus intermedius? Taxonomic revision and emergence of multi-drug resistance. J. Small Anim. Pract., v.53, p.147-154, 2012.

CLSI. Performance standards for antimicrobial disk and dilution susceptibility tests for bacteria isolated from animals; approved standard. 3.ed. Philadelphia: Clinical and Laboratory Standards Institute, 2008.

DEVRIESE, L.A.; HERMANS, K; BAELE, M. et al. Staphylococcus pseudintermedius versus Staphylococcus intermedius. Vet. Microbiol., v.133, p.206-207, 2009.

FAZAKERLEY, J.; WILLIAMS, N.; CARTER, S. et al. Heterogeneity of Staphylococcus pseudintermedius isolates from atopic and healthy dogs. Vet. Dermatol., v.21, p.578-585, 2010.

FENG, Y.; TIAN, W.; LIN, D. et al. Prevalence and characterization of methicillin-resistant Staphylococcus pseudintermedius in pets from South China. Vet. Microbiol., v.160, p.517-524, 2012.

FORBES, B.A.; BOMBICINO, K.; PLATA, K. et al. Unusual form of oxacillin resistance in methicillinresistant Staphylococcus aureus clinical strains. Diagn. Micr. Infec. Dis., v.61, p.387-395, 2008. 
GRIFFETH, G.C.; MORRIS, D.O.; ABRAHAM, J.L. et al. Screening for skin carriage of methicillinresistant coagulase-positive staphylococci and Staphylococcus schleiferi in dogs with healthy and inflamed skin. Vet. Dermatol., v.19, p.142-149, 2008.

GUARDABASSI, L.; LOEBER, M.E.; JACOBSON, A. Transmission of multiple antimicrobial-resistant Staphylococcus intermedius between dogs affected by deep pyoderma and their owners. Vet. Microbiol., v.98, p.23-27, 2004

HARTMANN, F.A.; WHITE, D.G.; WEST, S.E.H. et al. Molecular characterization of Staphylococcus intermedius carriage by healthy dogs and comparison of antimicrobial susceptibility patterns to isolates from dogs with pyoderma. Vet. Microbiol., v.108, p.119131, 2005.

HAUSCHILD, T.; WÓJCIK, A. Species distribution and properties of staphylococci from canine dermatitis. Res. Vet. Sci., v.82, p.1-6, 2007.

IHRKE, P.J. An overview of bacterial skin-disease in the dog. Br. Vet. J., v.143, p.112-118, 1987.

KANIA, S.A.; WILLIAMSON, N.L.; FRANK, L.A. et al. Methicillin resistance of staphylococci isolated from the skin of dogs with pyoderma. Am. J. Vet. Res., v.65, p.1265-1268, 2004.

KAWAKAMI, T.; SHIBATA, S.; MURAYAMA, N. et al. Antimicrobial susceptibility and methicillin resistance in Staphylococcus pseudintermedius and Staphylococcus schleiferi subsp coagulans isolated from dogs with pyoderma in Japan. J. Vet. Med. Sci., v.72, p.1615-1619, 2010.

LOEFFLER, A.; LINEK, M.; MOODLEY, A. et al. First report of multiresistant, mecA-positive Staphylococcus intermedius in Europe: 12 Cases from a veterinary dermatology referral clinic in Germany. Vet. Dermatol., v.18, p.412-421, 2007.

MEDLEAU, L.; LONG, R.E.; BROWN, J. et al. Frequency and antimicrobial susceptibility of Staphylococcus species isolated from canine pyodermas. Am. J. Vet. Res., v.47, p.229-231, 1986.
MULVEY, M.R.; CHUI, L.; ISMAIL, J. et al. Development of a Canadian standardized protocol for subtyping methicilin-resistant Staphylococcus aureus using Pulsed-Field Gel Electrophoresis. J. Clin. Microbiol., v.39, p.3481-3485, 2001.

OLSSON-LILJEQUIST, B.; KÕLJALG, S.; KARLSSON, I. et al. Calibration of fusidic acid disk diffusion susceptibility testing of Staphylococcus aureus. APMIS, v.110, p.690-696, 2002.

ONUMA, K.; TANABE, T.; SATO, H. Antimicrobial resistance of Staphylococcus pseudintermedius isolates from healthy dogs and dogs affected with pyoderma in Japan. Vet. Dermatol., v.23, p.17-e15, 2012.

REES, C.A. New drugs in veterinary dermatology. Vet. Clin. N Am-Small, v.29, p.1452-1454, 1999.

RUSCHER, C.; LUEBKE-BECKER, A.; WLEKLINSK, C.G. et al. Prevalence of Methicillinresistant Staphylococcus pseudintermedius isolated from clinical samples of companion animals and equidaes. Vet. Microbiol., v.136, p.197-201, 2009.

SAASAKI, T.; KIKUCHI, K.; TANAKA, Y. et al. Reclassification of phenotypically identified Staphylococcus intermedius strains. J. Clin. Microbiol., v.45, p.2770-2778, 2007.

SCHISSLER, J.R.; HILLIER, A.; DANIELS, J.B. et al. Evaluation of Clinical Laboratory Standards Institute interpretive criteria for methicillin-resistant Staphylococcus pseudintermedius isolated from dogs. J. Vet. Diagn. Invest., v.21, p.684-688, 2009.

TOMA, S.; COLOMBO, S.; CORNEGLIANI, L. et al. Efficacy and tolerability of once-daily cephalexin in canine superficial pyoderma: an open controlled study. J. Small Anim. Pract., v.49, p.384-391, 2008.

WEESE, J.S.; VAN DUIJKEREN, E. Methicillinresistant Staphylococcus aureus and Staphylococcus pseudintermedius in veterinary medicine. Vet. Microbiol., v.140, p.418-429, 2010.

WHITE, S.D.; BROWN, A.E.; CHAPMAN, P.L. et al. Evaluation of aerobic bacteriologic culture of epidermal collarette specimens in dogs with superficial pyoderma. J. Am. Vet. Med. Assoc., v.226, p.904-908, 2005. 